\title{
Medical error: the second victim
}

\section{The doctor who makes the mistake needs help too}

When I was an intern, a resident failed to identify the electrocardiographic signs of the pericardial tamponade that would rush the patient to the operating room late that night. The news spread rapidly, the case tried repeatedly before an incredulous jury of peers, who returned a summary judgment of incompetence. I was dismayed by the lack of sympathy and wondered secretly if I could have made the same mistake-and, like the hapless resident, become the second victim of the error.

Strangely, there is no place for mistakes in modern medicine. Society has entrusted physicians with the burden of understanding and dealing with illness. Although it is often said, "doctors are only human," technological wonders, the apparent precision of laboratory tests, and innovations that present tangible images of illness have in fact created an expectation of perfection. Patients, who have an understandable need to consider their doctors infallible, have colluded with doctors to deny the existence of error. Hospitals react to every error as an anomaly, for which the solution is to ferret out and blame an indi- vidual, with a promise that "it will never happen again." Paradoxically, this approach has diverted attention from the kind of systematic improvements that could decrease errors. Many errors are built into existing routines and devices, setting up the unwitting physician and patient for disaster. And, although patients are the first and obvious victims of medical mistakes, doctors are wounded by the same errors: they are the second victims.

Virtually every practitioner knows the sickening realization of making a bad mistake. You feel singled out and exposed - seized by the instinct to see if anyone has noticed. You agonize about what to do, whether to tell anyone, what to say. Later, the event replays itself over and over in your mind. You question your competence but fear being discovered. You know you should confess, but dread the prospect of potential punishment and of the patient's anger. You may become overly attentive to the patient or family, lamenting the failure to do so earlier and, if you haven't told them, wondering if they know. ${ }^{1-3}$

Sadly, the kind of unconditional sympathy and sup- 
port that are really needed are rarely forthcoming. While there is a norm of not criticizing, ${ }^{4}$ reassurance from colleagues is often grudging or qualified. One reason may be that learning of the failings of others allows physicians to divest their own past errors among the group, making them feel less exposed. ${ }^{5}$ It has been suggested that the only way to face the guilt after a serious error is through confession, restitution, and absolution. ${ }^{6}$ But confession is discouraged, passively by the lack of appropriate forums for discussion, and sometimes actively by risk managers and hospital lawyers. Further, there are no institutional mechanisms to aid the grieving process.

Even when mistakes are discussed at morbidity and mortality conferences, it is to examine the medical facts rather than the feelings of the patient or physician. In the absence of mechanisms for healing, physicians find dysfunctional ways to protect themselves. They often respond to their own mistakes with anger and projection of blame and may act defensively or callously and blame or scold the patient or other members of the health care team. Distress escalates in the face of a malpractice suit. In the long run, some physicians are deeply wounded, lose their nerve, burn out, or seek solace in alcohol or drugs. ${ }^{6}$

My observation is that this number includes some of our most reflective and sensitive colleagues, perhaps most susceptible to injury from their own mistakes. What should we do when a colleague makes a mistake? How would we like others to react to our mistakes? How can we make it feel safe to talk about mistakes? In the case of an individual colleague, it is important to encourage a description of what happened and to begin by accepting this assessment and not minimizing the importance of the mistake. Disclosing one's own experience of mistakes can reduce the colleague's sense of isolation. It is helpful to ask about and acknowledge the emotional impact of the mistake and ask how the colleague is coping. If the patient or family is not aware of the mistake, the importance of disclosure should be discussed.

The physician has an ethical responsibility to tell the patient about an error, especially if the error has caused harm. ${ }^{7}$ We should acknowledge the pain of implementing this imperative. We can, however, convey the great relief it can be to admit a mistake, and that, confronted by an empathic and apologetic physician, patients and families can be astonishingly forgiving. Only then is it appropriate to approach the mistake with a problem-solving focus and to explore what could have been done differently and what changes can be made at the individual and institutional level to prevent recurrence.

In the case of the misread electrocardiogram, the educational and emotional experience for the resident - and the team-would have been transformed if a respected senior clinician had led an open discussion of the incident and acknowledged the inevitability of mistakes. Nurses, pharmacists, and other members of the health care team are also susceptible to error and vulnerable to its fallout. Given the hospital hierarchy, they have less latitude to deal with their mistakes: they often bear silent witness to mistakes and agonize over conflicting loyalties to patient, institution, and team. They, too, are victims.

I'll conclude with an assignment for the practicing doctor: think back to your last mistake that harmed a patient. Talk to a colleague about it. Notice your colleague's reactions and your own. What helps? What makes it harder? Physicians will always make mistakes. The decisive factor will be how we handle them. Patient safety and physician welfare will be well served if we can be more honest about our mistakes to our patients, our colleagues, and ourselves.

References

$1 \mathrm{Wu}$ AW, Folkman S, McPhee SJ, et al. Do house officers learn from their mistakes? JAMA 1991;265:2089-2094.

2 Christensen JF, Levinson W, Dunn PM. The heart of darkness: the impact of perceived mistakes on physicians. J Gen Intern Med 1992;7:424-431.

3 Newman MC. The emotional impact of mistakes on family physicians. Arch Fam Med 1996;5:71-75.

4 Rosenthal MM. The Incompetent Doctor. Behind Closed Doors. Buckingham, England: Open University Press, 1995.

5 Terry JS, Fricchione GL. Facing limitation and failure. The Pharos 1985;Fall:13-18.

6 Hilfiker D. Healing the Wounds. A Physician Looks at His Work. New York: Penguin; 1985.

7 Wu AW, Cavanaugh TA, McPhee SJ, et al. To tell the truth: ethical and practical issues in disclosing medical mistakes to patients. J Gen Intern Med 1997;12:770-775. figure is less than a quarter of that, but it's still enough to cause a substantial spare tire when multiplied over a lifetime, write researchers from the US National Institutes of Health ( $N$ Engl J Med 2000;342:861-867). Volunteers in a study of holiday excess overestimated their weight gain by about $400 \%$ - but this did not inspire them to lose any of it over the following summer. 